\title{
IDENTITY AND GLOBALISATION
}

\author{
Tinatin Sabauri ${ }^{1}$, Salome Pataridze ${ }^{2}$ \\ ${ }^{1}$ M.A. Ms., Georgia, E-mail: tinatinsabauri@yahoo.de \\ ${ }^{2}$ PH.D Student, Ms., Georgia, E-Mail: salome.pataridze@iliauni.edu.ge
}

\begin{abstract}
The main features of globalization and identity are discussed in this paper. There are talking about the essence of globalization, the historical stages, the directions and the main signs. Here is analyzed the views of the researchers of globalization, hyper globalists, skeptics, transformationists on this topic. Here are some historical analogies of globalization on the examples of political globalization, economic globalization and cultural globalization.

Identity is analyzed as a counterweight to globalization postulates. Also is talked about religion as a "peculiar" globalization essence.
\end{abstract}

Keywords: Globalization, identity, religion.

\section{INTRODUCTION}

In the modern world the argument over whether it is possible to maintain the diversity of cultures in the process of globalization and modernization, without less of identity, continues to this day. A person doesn't belong to any culture from the birth. A child learns the language of the culture as a result of socialization and that's why the culture is not meant as a separate creative act but also the universal attitude to the world. Categories such as: nation, ethnicity, race and religion are used to express different identity marks. It should be noted, that in the modern world, in many cases many individuals are found to belong to each other, who sometimes are in conflict and the person is faced with the difficult choice. In the USA, who can imagine own place in society so that not mention his old roots: African, Irish, Spanish, Italian. Therefore identity was viewed as a collective treasure made from all of those elements, which provided it with something special "dosage" but found that it could be lost and that's why globalization was in danger. Its crushing wave ran over the world's diverse cultures. In the article will be discussed the risks and benefits of different views of globalization. The latter is based on the nation, that globalization instead of destruction creates conditions for cultural formation and development, because it is identity of the predecessor modernity.

The term Globalization means creation of unified global society gradual erasing of national and state differences, abolishment of borders and canceling of restrictions. There are various content differences in this term. The first is Internationalism, when globalization means international relations activation and diminishing border roles. The second is liberalization, which is expressed in open-integrated economics. The third means universalization or wide spreading material or spiritual values all over the world. The fours are mastering western civilization or westernization and, first of all, its American form. However, westernization is considered as union of European countries against globalization. And the last, globalization is determination, when geographical location, distance and frontiers lose their original meaning. 
There are three categories of globalization determines and researchers: hyperglobalists, sceptics and transformators. They have different views about the origin of globalization and its spreading.

\section{THE MAIN ISSUE AND DISCUSSION}

According to the present meaning of globalization there are a lot of analogues in mankind history. From this list we highlight cultural globalization. We find cultural globalization in:

1. In the era of Macedonia, as a result of eastern and Greek cultures synthesis, for example Elinism.

2. In Roman Empery as a result of Latin language.

3. In Byzantine Empery as a result Orthodox religion and Greek language.

4. In the age of Christ, when Christian society united.

5. Arab Empery on the basis of Islam religion and Arabic language.

6. In the Osmania Empery on the basis of Turkish ethnos.

7. In British Empery due to technical progress. Exchange of information was rapid and every day occurrence among colonies.

8. In Russian Empery as Russification, but united culture was not created.

9. In Soviet Union cultural globalization was obvious. A new historical unity "Soviet people" was created.

It is clear, that globalization is very complex and completed process. Interestingly, to what extent is possible, on the one hand, global political, economic or cultural processes, and on the other hand, local interests coexistence, that in some cases complete or resist one another.

Mainly, Identity is opposite of Globalization. Identity is, in its turn, is an attempt of maintaining dignity and traditions. Its mechanisms are very complex. Defining its meaning began in ancient world from Socrates word: "Know yourself" and it continued with Freud's attempts analyzing a person's anigmatic side. Nowadays this issue is more actual, as lots of people commits a crime by the name of religious, ethnical and national or other identities. In modern society we live in the structural frame, which define our existence. We live our gender, ethnic, nationality and etc. As socially institutional identities. In any age the concept of "Identity" was used by certain groups of people, who believed that they are one distinctive belonging was superior to others. For some it was nation, for others- religion or class. When people feel unsafe because of religion, this is religious belonging that is defined as their identity. But if their native language becomes endangered, than cobelivers fight each other conflict between Turkish and Curds. Consequently, we can conclude, that it there is a kind of hierarchy in the process of creating identity, it is not static; moreover, relations among them may totally change.

Identity is not only once defined thing, it is transforming and constructed during its existence. Our inborn identity is not numerous: Sex, color... (MAALOUF 2007, 36). But even sex is defined by social environment, in which we grow up: The born of women in London and in Qabul is not the same, it is said about color. That's why the thing that determines our belonging is others influence (relatives, cobeliever, cocitizens). But motivation is belonging to one specific group. According to the above- mentioned notions we can discuss identity as a learnt phenomenon, which you study at different stages of development, however, there may be the other opportunity for an individual chooses himself/herself identity that he/she realizes.

Each category of identity gets its meaning in a concert social-cultural environment. Those ways and means by which cultural establishes certain borders, is essential for understanding identity. Each culture has its own distinctive methods to make the world classification. By classification system culture offers different approaches how to define social environment and give it its meaning. Identity and difference is marked symbolically. Symbolic outlining means defining social relations, who may be a group member and who not: respectively, identity depends on differences.

\section{CONCLUSIONS AND RECOMMENDATIONS}

Within the work the polling will be held in adolescents and adults living in Georgia. The polling aims to analyze the notions of globalization and identity, civic and cultural values, religion and global citizenship, how to pose a threat to the other or how much it contributes to the development and establish a foothold. 


\section{REFERENCE LIST}

Maalouf, Amin (2007) Les identitesmeurtrieres. Impress; Tbilisi.

Formation of Identity in multicultural environment (2015) Editor: GvantsaBurduli. Development of international Model for Cultural Reform in Multicultural Education and Cultural Diversity Training. Tbilisi.

Hobsbawm, Eric (2007) Globalisation, Democracy and Terrorism.London. 